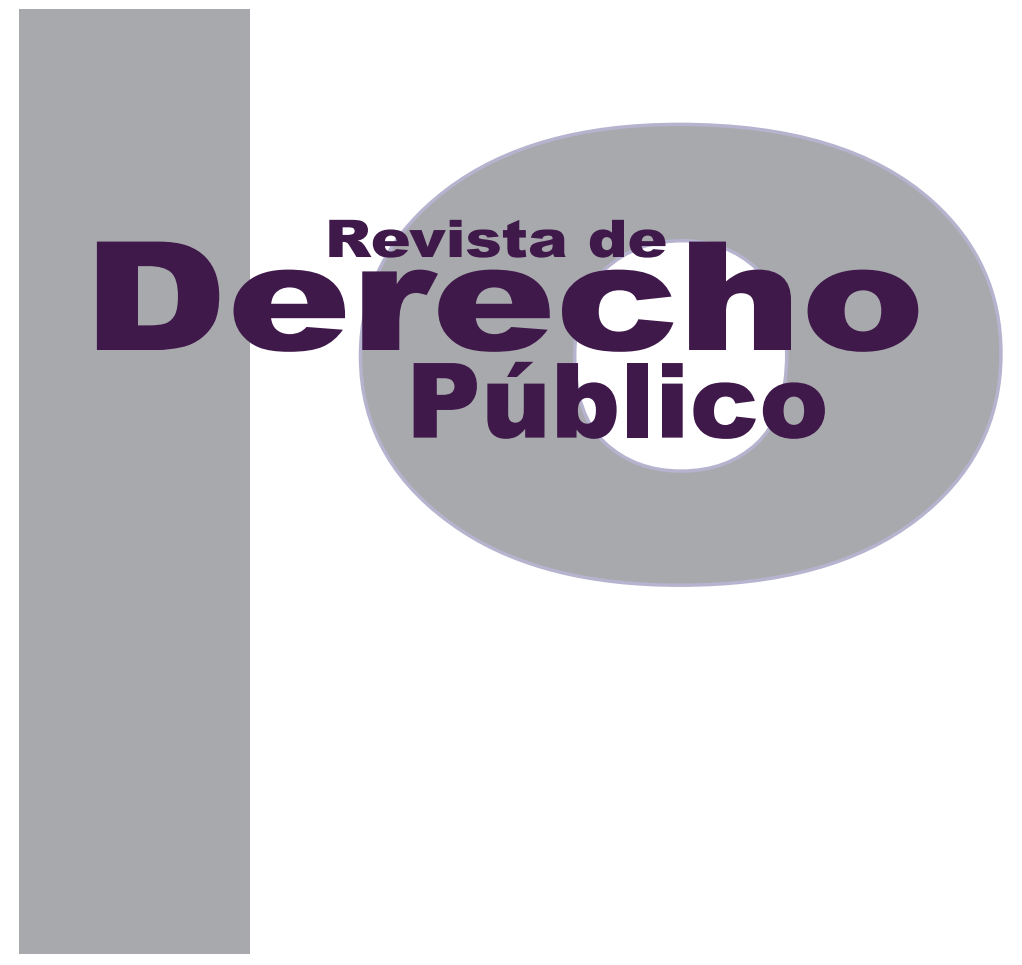

\title{
DERECHO ECONÓMICO Y GÉNERO: ALIANZA PARA LA ERRADICACIÓN DE LOS EFECTOS ADVERSOS DEL DESARROLLO CONTRA LA MUJER COLOMBIANA
}

LUIS Miguel Hoyos RoJAS

Universidad de los Andes

Facultad de Derecho

Revista de Derecho Público N. ${ }^{\circ} 30$

Enero - Junio de 2013. ISSN 1909-7778 


\title{
Derecho económico y género: alianza para la erradicación de los efectos adversos del desa- rrollo contra la mujer colombiana*
}

\author{
Luis Miguel Hoyos Rojas**
}

\begin{abstract}
RESUMEN
Este documento presenta la propuesta de Análisis del Derecho Económico con una Perspectiva de Género, para demostrar que pese a la existencia de una construcción constitucional y jurisprudencial que responde al desarrollo armónico de todos y todas en los sectores socioeconómicos, aún existen temas fundamentales que el derecho debe definir. En este, se partirá de la convicción que el derecho económico todavía tiene mucho que aportar a los procesos de desarrollo y que solamente un intercambio entre las disciplinas (derecho económico y género) podrá promover intervenciones encaminadas a impulsar el bienestar de la mujer de la población colombiana. En definitivo, se partirá de la concepción de que "género" es la perspectiva que dará cuerpo al verdadero objetivo del dere-
\end{abstract}

\section{ABSTRACT}

This paper presents the analysis of the economic law proposal with a gender perspective, to demonstrate that despite the existence of a constitutional and jurisprudential construction which responds to the harmonic of all development and all in the socio-economic sectors, there are still fundamental issues that the right must be defined. In this, it will depart from the conviction that economic law still has much to contribute to the development process and that only an exchange between disciplines (economic law and gender) may promote interventions aimed at promoting the welfare of the women of the Colombian population. In final, it will depart from the conception that "gender" is the perspective that will give body to the true aim of economic law in the realization of the ideals of rea-

El presente escrito es resultado de la investigación "Género, desarrollo y memoria histórica: la invisibilidad de la mujer colombiana".

** Investigador en derecho constitucional comparado y género. Investigador del grupo de investigación Pensar (en) Género, del Instituto de Estudios Sociales y Culturales PEnSAR, de la Pontificia Universidad Javeriana de Bogotá D. C. Miembro extranjero de la Asociación Argentina de Derecho Constitucional y par evaluador de la Red Colombiana de Semilleros de Investigación (REDCoLsı). Actualmente, coinvestigador en el megaproyecto "Para contribuir a la erradicación de la violencia basada en género en los municipios de Magangue, corregimiento de San Basilio de Palenque -Mahates- y Buenaventura (Colombia)" que dirige el Grupo de Investigación Pensar en Género y el Grupo de Investigación en Derecho Privado de la Pontificia Universidad Javeriana de Bogotá D.C. Actual consultor, investigador y miembro del grupo de investigación en desarrollo social y económico del Centro para el Desarrollo Social y Económico de Colombia (CEDESCOL). Beneficiario-Becario para estudios de Maestría en Harvard Law School, Cambridge, Massachusetts (Estados Unidos). Correo: "hoyos.luis@javeriana.edu.co" 
cho económico en la materialización de los ideales de equilibrio razonable de desarrollo para el país, inspirado desde la Constitución de 1991.

Palabras clave: derecho y desarrollo, género, inclusión social, derechos fundamentales y economía constitucional. sonable balance of development for the country inspired from the 1991 Constitution.

KEY WORDS: LaW and Development, Gender, Social Inclusion, Fundamental rights and Constitutional Economy. 


\section{SUMARIO}

Introducción - I. DERECHO ECONÓMICO Y DESARROLLO EN COLOMBIA - A. El derecho económico y su poco protagonismo en el desarrollo de Colombia - B. La deuda del derecho económico con la mujer colombiana en el proceso de desarrollo y replanteamiento del derecho económico - II- EQUIDAD DE GÉNERO EN EL DERECHO ECONÓMICO COMO INSTRUMENTO QUE AMINORA EL IMPACTO ADVERSO DEL DESARROLLO EN LA MUJER COLOMBIANA - A. Una necesidad fáctica - B. ¿ por qué la mujer? - III. EL GENDER MAINSTREAMING (MARCO ANALÍTICO DE HARVARD) EN LOS ANÁLISIS DEL DERECHO ECONÓMICO COLOMBIANO. UNA PROPUESTA PARA PRESCINDIR DEL GENDER BLINDNESS Y LA INVISIBILIDAD DE LA MUJER EN LOS PROCESOS DE DESARROLLO - A. Presentación - B. El gender mainstreaming $-C$. El gender mainstreaming en los análisis del derecho económico colombiano de cara a los procesos de desarrollo - 1. Los inicios - 2. La propuesta propiamente dicha - D. Componentes básicos del gender mainstreaming en los análisis del derecho económico en Colombia - 1. El contexto de inequidad - 2. La aplicación del proceso de análisis de las asimetrías de género en el desarrollo - 3. Las estructuras y los mecanismos - 4. El seguimiento y evaluación. - IV. CONCLUSIONES - Bibliografía. 


\section{Introducción}

La idea de generar un desarrollo incluyente en Colombia solo se comenzó a discutir con rigor académico a partir de 1991, con la expedición de la Constitución Política. En muchas otras partes del mundo, sin embargo, diversas concepciones relacionadas con el tema del progreso y el desarrollo en términos económicos, con una perspectiva incluyente, ya venían siendo discutidas desde 1945 (Arndt, H. W., 1987).

La Carta de 1991 logró incluir un capítulo sobre el régimen económico y la intervención del Estado en la economía (Kalmanovitz, 2001), que a manera de propuesta innovadora generó la aparición de principios para la realización del bienestar de todos y todas.

En su sentido más amplio, Colombia entró a definir en la reforma constitucional de 1991 su propio proceso de desarrollo -entendido este en los términos de Kalmanovitz, como el "conjunto de factores políticos, culturales y económicos que definen un país como moderno y desarrollado" (Kalmanovitz, 2001. Reforma que mejoró la visión de desarrollo establecida desde el Plan General de Desarrollo Económico y Social 1960-1970, expedido durante la administración del presidente Alberto Lleras Camargo.

De esta manera, la Constitución de 1991 situó en nuestro país lo que se conocía globalmente como revolución económica (De Melo, 1991), dándonos nuevas luces para el proceso de desarrollo y modernización económica que adelantaba el país. Pero, tal visión de desarrollo, no obstante prometedora, siguió refiriéndose a la acumulación de capital para la industrialización y la apertura de las economías -revolución económica-, dejando atrás la formulación de políticas y análisis para la igualdad, diseñadas para la realización de las capacidades humanas en el marco de la equidad social. Situación que ya había sido expuesta en el año de 1958 en el informe del sacerdote Louis Joseph Lebret, Estudio sobre las condiciones del desarrollo en Colombia, también Ilamado Informe Lebret, cuando puso en evidencia que en nuestro país la puesta en marcha de programas y proyectos de desarrollo social y económico no correspondía con la realidad nacional, por la reiteración del gobierno en generar y ratificar la exclusión social desde los procesos económicos (López, 1994).

Lo seguro es que cuando en el mundo se hablaba de interacción entre economía y desarrollo desde una perspectiva incluyente o "estrategia de crecimiento y desarrollo con equidad" (Bravo y Contreras, 2004), tal interacción no llegó al país, y los iniciales avances que sobre esta se forjaron fueron alimentados por diversas corrientes que no consiguieron crear alianzas entre enfoques incluyentes y el capital, para la generación de oportunidades.

Fue entonces hasta 1997, cuando la Corte Constitucional atendiendo a la generación de enfoques inspirados en la distribución de oportunidades, en sus primeros fallos consiguió erigir un cuerpo axiomático para las promesas inmersas en el desarrollo de Colombia, logrando un mandato de optimización que generó la participación activa de todos y todas en los procesos que sufría en aquel entonces el país. 
La Corte Constitucional interpretó que los procesos de modernización y de desarrollo en Colombia debían generar el equilibrio razonable entre los beneficiarios de toda la economía y la sociedad, garantizando la realización de oportunidades para todas las personas, más en particular, para aquellas de menores ingresos (Corte Constitucional, C-233/97 y C-150/03).

Con esta posición la Corte dio a comprender que el proceso de desarrollo definido en la reforma constitucional de 1991 debía contar con formas, mecanismos legales y otra serie de posibilidades que auspiciaran la equidad social y económica en beneficio de todos.

Por lo que según la interpretación de la Corte era necesario diseñar marcos de análisis social y políticas de inclusión de frente al desarrollo, que a manera de instrumentos políticos, legales y sociales apuntaran a la generación de indicadores y guías para la equidad (Corte Constitucional, C-233/97 y C-577/05), alcanzando a acordar las bases axiológicas del desarrollo y el régimen económico en nuestro país:

(...) Normas orientadas a establecer la producción, distribución, utilización y consumo de bienes y servicios públicos, buscando la racionalización de la actividad económica con especial énfasis en la protección del empleo y en la promoción de la productividad y la competitividad nacionales. Favoreciendo el cabal cumplimiento de las prerrogativas inherentes a la libre iniciativa y a la vez, procurar la protección del interés público comprometido dentro del marco de las responsabilidades sociales a las que alude la Constitución (Corte Constitucional, C-233/97). (Paréntesis míos).
Esta elucidación de la Corte marcaría un debate mucho más amplio y antiguo que se refiere a la relación entre derecho, economía y desarrollo y, a partir de la Constitución de 1991, la relación entre derecho económico e inclusión social.

En un sentido más amplio podemos creer que Colombia ha constituido una gran base para la alianza entre economía y desarrollo $(E+D)$, permitiéndose conquistar y superar ciertas necesidades sociales en el largo camino hacia el progreso. Pero, lo cierto es que tal base ha evolucionado desde la predominancia de la economía, pues al estudiar las relaciones entre economía y derecho en Colombia, tenemos que determinar que jurídicamente esta interacción solo se ha entendido desde la concepción de actividad económica (Arango, Flórez, Arosemena, 2004).

En nuestro país solo se vienen considerando como acciones económicas y para el desarroIlo - entendido en los términos de Del Vecchio-, aquellas que tienen por objeto la adquisición o circulación de bienes y servicios, en las cuales los medios son adecuados a los fines de esta especie (Del Vecchio, 1967), siendo extrañas a la economía y al desarrollo las acciones dirigidas a fines netamente sociales o humanísticos, más allá de la realización patrimonial y adquisitiva, que son desestimadas por la economía porque derivarían posiblemente en una pérdida en lugar de una ganancia.

Es esta la configuración-visión donde el derecho y la perspectiva social solo tienen un papel subordinado a aquellas aproximaciones teóricoeconómicas que instrumentalizan al derecho como un ente de regulación normativa para el 
desarrollo, que llevó al pais a desarrollar los efectos extremos del sistema capitalista. (Alviar, 2001). Enfoque existente en Colombia que ha generado la pérdida del espacio de discusión jurídica y el asentamiento del debate en temas técnico-económicos, que no entienden el análisis de ciertas instituciones y conceptos sociales que promueven y aseguran la asignación de recursos a través de la participación equitativa en los sectores sociales, cuyo efecto es un mejor desempeño económico que propugna la eliminación de cualquier forma de discriminación.

Es en esta representación donde nace la importancia de replantear desde el espacio de discusión teórico jurídico, un "cómo" que permita en Colombia esa anhelada interacción entre economía y desarrollo desde una perspectiva incluyente. La realidad es que las iniciales aproximaciones teórico-económicas referidas a "utilidad, relación de medio-fin, actividad y apertura económica, regulación de la economía y de los mercados, consumidores, competencia comercial, Mercado Bursátil y de Capitales", etc., que entendieron en cierto momento histórico el desarrollo y conceptualizaron al derecho como instrumento subordinado por la economía en nuestro país, hicieron perder la sensibilidad social y el objetivo del progreso, que son en todo momento, las personas.

Los conceptos económicos en los que se ha definido y entendido el proceso de desarrollo en Colombia nunca incluyeron la definición de sólidos mecanismos de intervención-acción extensivos a los sectores menos privilegiados, siendo esta una debilidad central que hoy se señala como una promesa incumplida que, además, eviden- cia que en nuestro país no ha existido una vinculación entre los procesos de desarrollo y las personas menos privilegiadas, para quienes la aplicación del concepto de desarrollo y toda su normatividad ha sido, desde un inicio, incierta.

En el mismo sentido, no hay duda alguna de que las mujeres son y no han dejado de ser el sector social que ha padecido históricamente la situación de desventaja en todo este proceso de desarrollo social y económico. Aun cuando hoy, por los menos formalmente, se reconoce la igualdad entre hombres y mujeres, el hecho es que no se puede desconocer que para ello las mujeres han tenido que recorrer un largo camino.

Lo cierto es que existe la necesidad de una propuesta de análisis del derecho económico con una perspectiva de género, que aproxime soluciones a favor de la mujer y contribuya a la erradicación de la discriminación que hoy se presenta en Colombia.

Este documento tiene como objetivo hacer una propuesta de análisis de la perspectiva de género en el derecho económico, para demostrar que pese a la existencia de una construcción constitucional y jurisprudencial que responde al desarrollo armónico de todos y todas en los sectores socioeconómicos, aún existen temas fundamentales que el derecho debe definir (por ejemplo, la diferencia salarial entre hombres y mujeres, etc.), y conjuntamente exponer los cambios esenciales que esta rama del derecho podría tener de ser posible esta relación.

En definitiva, este documento partirá de la convicción de que el derecho económico aún tiene 
mucho que aportar a los procesos de desarroIlo, y que solamente de un intercambio entre las dos disciplinas (derecho económico y género) y los objetivos de desempeño económico y los de equidad desde la perspectiva de género, se podrá promover intervenciones encaminadas a impulsar el bienestar de la mujer de la población colombiana. Desde esa presentación el género será el cuerpo que dará forma al verdadero objetivo del derecho económico en la materialización de los ideales de equilibrio razonable de desarrollo para el país, inspirado desde la Constitución de 1991.

\section{DERECHO ECONÓMICO Y DESARROLLO EN COLOMBIA}

\section{A. El derecho económico y su poco protagonismo en el desarrollo de Colombia}

Me refiero al desarrollo entendido en la perspectiva social y económica, lo que el derecho económico hace por este, que viene a ser el aspecto más importante, pues alude a la atención de aquellas personas que más lo requieren en la sociedad, no tratándose de empresas, industrias o el Estado mismo, sino de las personas en sí y sus necesidades.

Concebiremos el concepto de desarrollo como aquel avance en los niveles de crecimiento económico, social, cultural y político de una sociedad o país (Stiglitz, 2002). Y desde el punto de vista económico, como la generación de oportunidades para la población y los medios para satisfacer sus necesidades.
Para lograr el desarrollo debe haber una justa y eficiente distribución de la riqueza nacional, que permita a la población acceder a los servicios básicos. En esta concepción, el desarrollo exige para su realización la creación de un entorno en el que las personas puedan ampliar su máximo potencial y llevar adelante una vida productiva y creativa de acuerdo con sus necesidades e intereses (Diez, 1996). Luego para el desarrollo las personas son la verdadera riqueza y, por lo tanto, implica ampliar las oportunidades para que cada persona pueda vivir una vida que valore (Amartya, 1998). El desarrollo es entonces mucho más que el crecimiento económico, que constituye solo un medio -si bien muy importante- para que cada persona tenga más oportunidades.

Así las cosas, para que existan más oportunidades lo fundamental es desarrollar las capacidades humanas: la diversidad de actividades que las personas pueden hacer o ser en la vida. Esto es, justipreciar las capacidades sensibles a los procesos de desarrollo, haber sido educado, acceder a los recursos necesarios para lograr un nivel de vida digno y poder participar de forma equitativa en el quehacer de la comunidad. Sin estas capacidades se restringe cuantiosamente la variedad de opciones disponibles y muchas oportunidades resultan inaccesibles.

En Colombia, en la última década, la pobreza ha afectado a casi la mitad de la población (PNUD, 2010). Los índices de desigualdad entre sectores de la sociedad han aumentado, y esto se ha traducido en mayores niveles de exclusión social, en el quebranto constante de oportunidades y en la restricción para que muchos y mu- 
chas accedan a oportunidades de superación en el marco del desarrollo, desmejorándose con esto toda posibilidad de un verdadero progreso en nuestras comunidades (Mesep, 2002).

Han sido ciertos grupos poblacionales ubicados bajo la línea de pobreza los que se han visto más afectados por este quebranto constante de oportunidades, en últimas, los que han sido excluidos: las mujeres. Ellas han sido históricamente las menos favorecidas por las dinámicas del mercado laboral, las que presentan mayores tasas de desempleo e informalidad, las que han sufrido una desventaja relativa en los ingresos laborales. Sobre todo las mujeres indígenas, afrocolombianas y en situación de desplazamiento forzado, debido a su condición de género o etnia o a su situación de desplazamiento, han enfrentado situaciones de carencia de oportunidades para generar ingresos que les ayuden a superar la situación de vulnerabilidad en la que actualmente se encuentran (PNUD, 2010).

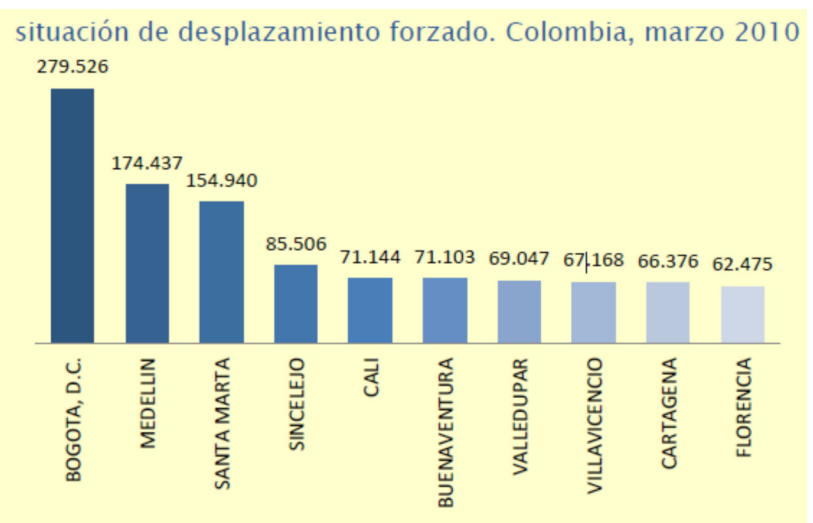

Fuente: Acción Social. Registro Único de Población Desplazada RUPD a marzo 31 de 2010

La existencia de indicadores que señalan que nuestro desarrollo se traduce en analfabetismo, estructura económica deficiente, poco ahorro económico por habitante, producción y tecnolo- gía desequilibrada, inminente desempleo, diferencias injustificadas en la distribución interna de la riqueza, entre otros, evidencia una mala asignación de los recursos, un desaprovechamiento de las oportunidades (PNUD, 2010), el protagonismo del derecho económico en el desarrollo, la falta de un buen criterio de política económica y de análisis no desde contextos jurídico-económicos, sino desde hegemonías netamente económicas (Layne \& Shawrs, 1993). Este cuadro deja en claro que no existen en el análisis del derecho económico colombiano instrumentos de política económica incluyente, como el llamado enfoque de derechos para el fortalecimiento de las capacidades humanas para el desarrollo (OEA, 2006), al que se refirió implícitamente la Corte Constitucional en el año de 1997.

El derecho económico colombiano en sus análisis nunca ha contemplado que la realización de las personas solo posible con la aplicación de un marco conceptual para el proceso de desarrollo -el enfoque de derechos para el fortalecimiento de las capacidades humanas-, que comprende la formulación de nuevos análisismarco, perspectivas incluyentes y otro tipo de políticas que buscan la realización de los derechos procurando fortalecer la capacidad humana (оIт, 2008).

Así las cosas, percibir el comportamiento de la economía nacional de frente al desarrollo e igualmente identificar y diferenciar aquellos cambios favorables o desfavorables que se producen en la vida económica al servicio de las personas ha sido una meta no lograda en CoIombia. Lo que significa que la función del derecho económico colombiano de proporcionar 
respuestas eficaces y eficientes a las exigentes y, por demás, cambiantes realidades económicas del país no ha sido cumplida. Situación que hace difícil construir una definición satisfactoria de desarrollo desde el derecho económico, máxime cuando se siguen detectando tendencias que no solo mancillan el proceso, sino que se resisten a ser corregidas por medio del establecimiento de justas y distribuibles reglas de juego neutrales para todos los actores sociales del desarrollo del país.

\section{B. La deuda del derecho económico con la mujer colombiana en el proceso de desarrollo y replanteamiento del derecho económico}

En nuestro país, tal como lo comprendimos anteriormente, el derecho económico no ha jugado un papel preciso en la participación y realización de las personas, circunstancia agravada para el caso de la mujer colombiana en los sectores del desarrollo y la economía (PNUD, 2005).

La lectura que podemos hacer de los inicios del desarrollo en Colombia señala a un derecho económico subordinado, concebido solo para efectos de reglamentar la economía, un derecho sin perspectivas y análisis incluyentes, un derecho generador de análisis económicos consistentes en estudios y evaluación de las fuerzas y potenciales instituciones del mercado y de la economía (Holesovsky, 1977), que responde solo a las exigencias de un positivismo clásico que excluye cualquier posibilidad de considerar problemas de equidad impersonal e interpersonal (Giddens, 1974).
Esto, traducido en la mujer colombiana, se convirtió en un aislamiento social y económico que la relegó mayoritariamente a la actividad doméstica, sin esperanzas de insertarse en el mercado de trabajo, donde los hombres ya venían vinculándose gradualmente. Situación que se agravó, producto de que bien entrado el siglo veinte tenían restringido el ejercicio de su ciudadanía y la mayoría de derechos económicos, sociales y culturales, con lo cual se las equiparaba a los menores y dementes en la administración de sus bienes, entre otras limitaciones.

Los análisis del derecho económico mostraban que las mujeres no solo tenían necesidad de mayores ingresos, sino que eran las menos prósperas y requerían un ingreso monetario decente y subsistente, como fundamento básico para su manutención y desarrollo como personas. Lo anterior sin dejar de mencionar que el imaginario social y la división de tareas por género/sexo tampoco fueron asimiladas en los análisis del derecho económico, que en sus inicios y todavía concibe a las mujeres como responsables del hogar y a los hombres como "ayudantes". Desde esta representación, las mujeres fueron incorpóreas en los análisis del derecho económico, ya que su labor socialmente no se consideró (Álvarez, 2010).

Por conveniencia o no, fue evidente que desde 1920 se vino sometiendo, denigrando y excluyendo a la mujer colombiana de los procesos de desarrollo social y económico (Steve, 1999). El desconocimiento de la capacidad jurídica y social de la mujer para dirigir sus procesos de desarrollo fue la más mezquina realidad de una subordinación socioeconómica que para ellas 
repercutió en un completo atraso histórico. Es en este mismo momento histórico donde se evidencian los principales efectos de la exclusión de la mujer de los análisis del derecho económico, y cuando florecen los primeros registros de la discriminación de género que creó la deuda del desarrollo y la economía con la mujer de nuestro país. Situación que con diverso grado de magnitud es verificada en toda la historia de los sectores de la economía colombiana, echando por tierra el principio jurídico que establece la Carta Constitucional de que a igual trabajo, igual salario, igual oportunidad en el desarrollo para todos (Harvey, 1997).

Ahora bien, para generar en Colombia cambios respecto al protagonismo de la mujer en los procesos de desarrollo resulta del todo interesante reafirmar la concepción del derecho económico que fue instalada desde la Constitución de 1991: aquel capaz de aminorar impactos de exclusión y de atraso a ciertos sectores de la sociedad.

De esta forma, debemos iniciar esbozando que el derecho económico debe ser comprendido como un conjunto de principios y normas sustancialmente de derecho público constitucional, que cumple finalidades sociales (Ackerman \& Golove, 1995).

La Constitución de 1991 revivió en Colombia la discusión doctrinal sobre esta rama del derecho, respecto de la cual muchos autores apuntan que nació constitucionalizada con un enfoque netamente socio-incluyente (Calderón, 2011). Aproximación doctrinal desarrollada por el profesor Cea (1979), quien acordó que el efectivo derecho económico era definido como: "el conjunto de principios y normas jurídicas que organizan la economía de un país y facultan a la autoridad para regularla en armonía con los valores de la sociedad nacional formulados en la Constitución".

El profesor Cea entendió que el derecho económico no se agotaba, ni mucho menos, en la Constitución y la economía, sino que comprendía el conjunto de principios, normas y medidas jurídicas en sus muy diversas jerarquías y especies, que consentían la realización social de todos. Visión que para todos los efectos es tomada como válida para esta investigación y que es en todo momento ajustable en Colombia.

Desde esta representación, hay que instruir en la asimilación de que el derecho económico tiene una naturaleza que jamás se ha pensado ni se ha instalado en nuestro país -científica social-, siempre que se le examine con una metodología interdisciplinaria no formalista, propia de la teoría económica.

Así, esta rama del derecho de nivel constitucional implicará en forma primordial la realización y progreso de los derechos fundamentales de las personas en materia socioeconómica, habilitando al legislador para regular el libre ejercicio de las garantías, pudiendo sin afectar su esencia, limitarlos o restringirlos, pero por ningún motivo eliminarlos.

Se asimila así al derecho económico con una visión netamente incluyente -una visión que jamás ha tenido y que de ser aplicada no hubiera excluido a las mujeres-, integrada por catego- 
rías jurídicas (elemento formal) y socioeconómicas (elemento material), de manera que su objeto de estudio pudiera ser bicéfalo e interdisciplinario, con lo cual se lograría encontrar los enlaces para la distribución de los recursos en materia económica. Pero,

¿cómo se reafirmaría el derecho económico en la realidad colombiana para efectos de aminorar el impacto adverso ocasionado a la mujer en los procesos de desarrollo?

De hecho, tal y como lo evidencian los informes sobre desarrollo del Programa de las Naciones Unidas para el Desarrollo (PNUD) y como apunta la propuesta mundial del desarrollo, donde se propone el análisis de los valores y formas de ejercicio del poder, de las elites y de la ciudadanía: enfatizando las experiencias positivas y sus resultados en favor del desarrollo incluyente, buscando establecer el bienestar humano como objetivo central del desarrollo mediante la transformación de las relaciones de género fuera de una visión economicista (PNUD, 2005).

En este entendido, desde el derecho económico debe plasmarse que la visión de la economía para el desarrollo deba ser real, social e incluyente, y como tal ponerse en ella radical atención, de tal manera que las decisiones y actividades institucionales que se realicen en esta materia respondan a una visión incluyente de la cuestión.

Es necesario desde el derecho económico proponer la igualdad o la reducción de las desigualdades o asimetrías, como elemento sine qua non del desarrollo, modificando la estructura económica de producción y distribución para que se produzca un crecimiento equitativo, y exigiendo también programas de desarrollo e inversiones que no dependan únicamente de los mecanismos de mercado, sino de los procesos de cooperación con enfoque incluyente.

Así, en lo que respecta al modelo de desarrollo por el que Colombia ha apostado desde 1991, concretado en el proyecto de modernización socioeconómica del país, se lograría fomentar el reparto de la participación plena e igualitaria de hombres y mujeres en la toma de decisiones. Por lo que estoy convencido de que el objetivo del desarrollo en Colombia es alcanzar una igualdad como apunta la Constitución de 1991, tanto en el acceso como en el control de los recursos económicos, y esto es a lo que debe responder el derecho económico como gestor del desarrollo en Colombia.

Luego no podremos hablar de progreso ni de desarrollo si no es sobre la base sólida de la igualdad de derechos y de oportunidades entre mujeres y hombres. Con esto el sistema social y económico colombiano para el desarrollo iría creciendo y desenvolviéndose a la par que se protegen los derechos de los excluidos y los vulnerados, que en el caso de Colombia tiene nombre: la mujer. En definitiva, el derecho económico como protagonista del desarrollo en Colombia debe apuntar a:

1. Establecer parámetros con los cuales medir la calidad de la participación con conciencia de género y el análisis de género participativo, así como desarrollar proyectos para monitorearlos en el proceso de desarrollo. 
2. Construir capacidad y compromiso del gobierno colombiano a fin de que se utilicen enfoques participativos para los procesos de desarrollo y se responda efectivamente a los intereses de género en el país.

3. Apoyar el desarrollo de las habilidades de defensoría de los grupos locales comprometidos con la igualdad de género, para que se involucren efectivamente en los procesos de desarrollo atendiendo a las reglas del derecho constitucional económico.

4. Integrar y utilizar la investigación y el análisis participativo feminista en la situación local de la pobreza, para orientar las prioridades sobre las cuales actuar.

\section{EQUIDAD DE GÉNERO EN EL DERECHO ECONÓMICO COMO INSTRUMENTO QUE AMINORA EL IMPACTO ADVERSO DEL DESARROLLO EN LA MUJER COLOMBIANA}

\section{A. Una necesidad fáctica}

La equidad de género es un requisito sine qua non para el logro del desarrollo que propende nuestro país, sin embargo, no se puede negar que las mujeres, constituyendo la mitad más uno de la población colombiana, tienen un acceso mucho más limitado a los recursos económicos y sociales que los hombres, y que este desequilibrio tiene efectos sociales negativos (Castillo, 1992).

La igualdad de género es considerada de suma importancia para lograr el bienestar de mujeres y hombres, y para llevar a cabo cambios socia- les e institucionales que produzcan un desarroIlo con justicia y oportunidades. La igualdad de género se refiere a la equivalencia de derechos, responsabilidades y oportunidades que deberían beneficiar a todas las personas, sin importar si son hombres o mujeres (оІт, 2011)

La perspectiva de género permite estudiar y comprender las asimetrías que existen entre hombres y mujeres (Millán \& Estrada, 2004). La función y situación social de hombres y mujeres es muy diferente, ya que mientras los hombres, en la gran mayoría de las culturas como en nuestro país, gozan de un estatus privilegiado que les permite obtener mejores salarios, más oportunidades de educación y empleo, la mujer se encuentra subordinada a un orden androcéntrico que la limita en todas las esferas de la actividad humana.

El hecho de que la mayor parte de la propiedad privada esté en manos de los hombres tiene consecuencias sociales de largo alcance y profundas repercusiones en la estructura misma de la sociedad, entre otras, en la feminización de la pobreza. La falta de derechos iguales al acceso y propiedad de la tierra y a la herencia tiene como consecuencia el empobrecimiento y la inseguridad de las familias.

La perspectiva de género, además, permite distinguir los diferentes aportes de mujeres y hombres a la sociedad desde el punto de vista económico, de cara al desarrollo. Por ejemplo, la contribución económica de las mujeres hasta hace poco era invisibilizada en las estadísticas, en razón a que no hacían una desagregación por sexos. 
La perspectiva de género en el derecho económico, en Colombia, permitiría concebir la participación de todos en la realización social de los derechos constitucionales económicos, fin máximo al que aspira la Carta en el continuo perfeccionamiento del concepto de Constitución económica, con el objetivo de dar aplicación a los principios de la equidad en el escenario económico de la sociedad, respondiendo a la exigencia que consagra la distribución de roles en el sector productivo de la economía, para la generación de alternativas de desarrollo dentro del contexto del enfoque de equidad y justicia en los sectores socioeconómicos del país.

Un primer avance de la alianza derecho económico y perspectiva de género aplicada al sector social más vulnerable estaría en generar un coherente análisis de las necesidades, para efectos de guiar la asignación de los beneficios y las cargas de la actividad económica de forma objetiva (Carrasquilla, 2001); en dotar al derecho económico colombiano de una nueva fuente (la más social y humana posible) que propugne por el encuadramiento de los fenómenos sociales de los más vulnerables a la norma y realidad económica, bajo los principios de equidad, igualdad y proporcionalidad; en buscar un desarrollo incluyente que logre concertar la capacidad humana y la reciprocidad entre hombres y mujeres como principio de la prosperidad y el bienestar socioeconómico.

Derecho económico y género representaría erigir una sociedad socioeconómica que suponga garantizar la total inclusión de mujeres y hombres en la dinámica del desarrollo de estrategias específicas, para que las personas o los grupos de la población que se encuentran en condiciones precarias puedan mejorar su situación actual, superando la clásica visión del derecho económico. El género en el derecho económico definitivamente compondrá la construcción de la equidad en las situaciones donde se requiere impulsar acciones que compensen o moderen las discriminaciones que afectan a unas y otros, para avanzar hacia la igualdad.

Introducir el género como categoría de análisis o como método de identificación y corrección de desigualdades, de manera transversal o eje conductor para esta rama del derecho en el contexto colombiano, implica a futuro positivos condicionamientos a las políticas públicas de equidad y a los planes, programas, proyectos y mecanismos de trabajo públicos en el contexto de oportunidades sociales y desarrollo en nuestro país. Pues son necesarios marcos de análisis que como el de género, reconocen una comprensión más amplia del conjunto de la dinámica económica y de las distintas actividades que el método de estudio del derecho económico no prevé ni previó jamás en Colombia (Hoyos, 2012).

En definitiva, el derecho económico con la perspectiva de género estaría orientado a:

1. Propender por el desarrollo objetivo de la igualdad y la no discriminación arbitraria que haga el Estado y sus organismos en materia económica.

En Colombia persiste el apotegma que predica: “fuera del ámbito económico para el derecho no hay más horizontes". En efecto, la meta de 
la perspectiva de género en el derecho económico colombiano delinearía una representación diferente sobre el concepto actual de regulación económica del Estado.

Actualmente lo que ocurre es que el derecho económico, solo este, desde su objeto de estudio hace énfasis en los análisis económicos y no en las diferencias sociales ni en las repercusiones-contradicciones que tiene para la propia economía y para la sustentabilidad humana no considerar las asimetrías sociales y económicas.

2. Propender por el desarrollo de una coherente remuneración para todos sin importar la actividad económica, garantizando el respeto a la moral y al reconocimiento de las capacidades humanas de todos y todas.

Un ejemplo claro de la inexistencia del enfoque de género en la aplicación del derecho económico en Colombia son las Ilamadas "brechas salariales por género", las cuales son profundas y persistentes a pesar de que todos los estudios que se han referido al tema han encontrado que los hombres reciben una remuneración mayor que las mujeres, y de que se documenta que las mujeres no solo han aumentado su participación en el mercado laboral sino que, en promedio, tienen más años de estudio que los hombres.

Considerando que las mujeres tienen, en promedio, 6\% más en años de educación que los hombres en el grupo de asalariados, es improbable que la explicación de la brecha salarial esté fundamentada en el aspecto educativo, lo que evidenciaría que sí existe algún grado de discriminación por género en el mercado laboral colombiano. Con la incorporación de relaciones equitativas de género serias se superarían no solamente estas realidades injustificadas presentes en la economía (Trubek \& Dezalay, 1997) sino que se convertirían en el indicador de realización social entre hombres y mujeres.

En definitiva, la propuesta de la inclusión de género en las relaciones del derecho económico instauraría la modificación de los fundamentos de la política económica para contribuir a la erradicación de los efectos adversos del sector económico hacia los involucrados, concretamente hacia la mujer.

\section{B. ¿Por qué la mujer?}

El campo de los estudios de género en Colombia es muy reciente. Por el contrario, las luchas de los movimientos de mujeres por acceder a sus derechos sociales y económicos comenzaron hace casi un siglo. En los años 70 aparecieron los estudios pioneros sobre mujer y educación en Medellín y Bogotá D. C. La inclusión de la categoría género en el derecho y la ciencia política solo comenzó con el Plan Decenal de Educación (1996-2004). La investigación en este campo ha sido orientada hacia las representaciones del sistema sexo/género en las prácticas educativas. Solo hasta el 2003 comienza a integrarse el componente de diversidad a raíz del impulso del programa Mujeres Constructoras de Paz y Desarrollo, políticas nacionales en género y diversidad en favor de la discapacidad, las migraciones forzadas y las diferencias étnicas. Se concluye que hace falta voluntad y políticas locales eficaces en género, diversidad y educa- 
ción para fomentar la investigación colaborativa en la construcción de una cultura incluyente respecto a la mujer.

De acuerdo con lo anterior, la categoría género ha sufrido un proceso reconstructivo para articular a la diferencia sexual otras distinciones como la clase, la etnia, la edad, la discapacidad y la opción sexual, pero respecto al empoderamiento de la mujer colombiana en los sectores de desarrollo del país es poco lo que se ha construido e investigado (Domínguez, 2005). Incluso, aun cuando se han realizado algunos progresos desde el derecho y la economía -Lineamientos de la política pública nacional de equidad de género para las mujeres 2012-2022- auspiciados por la Constitución Política, la sociedad colombiana sigue fallando a la mujer particularmente en su realización socioeconómica, y en momentos claves de su vida: su adolescencia y vejez.

La mujer colombiana siempre ha estado en una posición desventajosa frente al hombre y sus procesos de desarrollo; la promoción de igualdad de género implica dar una atención explícita a las necesidades y las perspectivas de las mujeres. Solo para el trimestre móvil junio - agosto de 2010, de acuerdo con los datos del Dane, la tasa de desempleo femenina se ubicó muy por encima de la tasa de desempleo masculina, $15.8 \%$ y $8.9 \%$ respectivamente. En las 13 áreas metropolitanas el desempleo alcanzó una tasa de $14.9 \%$ en las mujeres y $10.9 \%$ en los hombres, evidenciando que la brecha de desempleo por sexo afecta también a las grandes ciudades (Dane, 2010).

En septiembre de 2012 el país celebró que por primera vez, en cerca de cuatro años, la tasa de desocupación bajó a un dígito. Pero, los últimos reportes diferenciados por género, publicados por el Dane, muestran que para las mujeres la desocupación todavía tiene dos dígitos, evidenciando un traspié en el concepto de desarrollo y de inclusión social. La tasa de desocupación del país en el período septiembre - noviembre de 2011 fue de 9,3\%. En el mismo lapso, esta tasa, para la población masculina, fue de $7 \%$ y para la femenina de 12,4\% (Dane, 2012).

Con esto, los datos del Dane muestran que de 7,2 puntos porcentuales que había de diferencia entre la tasa de desempleo de hombres y la de mujeres en 2001, se pasó en 2011 a una diferencia de 5,4\%, y al mismo tiempo que hay efectos negativos de consideración sobre las relaciones de poder y expectativas de los hombres y niños debido a los estereotipos sobre lo que significa ser de sexo masculino en algunas poblaciones de Colombia.

Es necesario, entonces, seleccionar la mujer y crear escenarios para incorporar su igualdad en las políticas y los programas que la Constitución fijó desde su expedición, para subsanar aquellas anomias jurídicas y sociales de la realidad con reconocimiento expreso a prestaciones productivas hacia ellas en los entornos sociales, buscando impulsarlas permanentemente desde políticas para el pleno ejercicio de sus derechos económicos, en el reconocimiento de su aporte a la vida económica del país y el acceso a condiciones dignas.

Desde esta configuración se lograría reivindicar el papel protagónico de la mujer en la sociedad colombiana; mitigar la opresión que la máquina 
económica ejerce contra ella en los procesos de desarrollo de nuestro país; obtener la identificación, visibilidad y remuneración de las contribuciones de ellas al funcionamiento del conjunto de la economía; e imponer a los sectores, la sociedad y el Estado la exigencia de los derechos fundamentales de corte económico y social aplicables a su beneficio, como una variación significativa al déficit socioeconómico en que se encuentran, para finalmente incorporar sus necesidades en las políticas económicas, ajustando un basamento constitucional aplicable a sus realidades sociales.

\section{EL GENDER MAINSTREAMING (MARCO ANALÍTICO DE HARVARD) EN LOS ANÁLISIS DEL DERECHO ECONÓ- MICO COLOMBIANO. UNA PROPUES- TA PARA PRESCINDIR DEL GENDER BLINDNESS Y LA INVISIBILIDAD DE LA MUJER EN LOS PROCESOS DE DESARROLLO}

\section{A. Presentación}

Como ya lo hemos analizado, en nuestro país las políticas económicas, comerciales y laborales han tenido impactos diferenciados sobre los hombres y las mujeres; los análisis y la elaboración de esas políticas han ignorado sistemáticamente el concepto de género, lo que ha ocasionado en la praxis una situación de fragilidad para la mujer (Beneria, 2001), sin dejar de mencionar la deuda que el derecho económico adquirió con la mujer colombiana al dejarla invisible en sus análisis económicos de frente al proceso de desarrollo del país.
Si bien los juristas y economistas colombianos han mostrado cierta sensibilidad al reconocer la desigualdad de género en los procesos socioeconómicos de nuestro país -fundamentalmente en la distribución de roles en el desarroIlo nacional-, en el ámbito macroeconómico y social de los acuerdos comerciales esta perspectiva no está incorporada, pues se parte del supuesto de que son espacios "neutrales" al género (Daeren, 2001).

Equivalentemente, en Colombia se ha avanzado en el análisis jurídico-económico que desarrolla investigaciones que reformulan teorías, metodologías y modelos tradicionales, logrando incluir la perspectiva de género como categoría analítica de la política económica (Kumar y López, 2001). Pero los resultados que fijan no alcanzan a trascender la realidad, en el compromiso de empoderar a la mujer.

Desde lo anterior, se puede entonces ultimar que uno de los principales problemas para formular los análisis de la economía y del derecho económico desde una perspectiva de género en Colombia, ha sido la propia teoría económica, la cual basa gran parte de sus estudios en el análisis de un ente representativo promedio que desconoce las diferencias entre hombres y mujeres, dada la aplicación del concepto de regulación económica que ignora las técnicas de enfoques idénticos o diferenciales (Gálvez, 2001).

Igualmente, en los procesos de desarrollo en Colombia, el llamado gender blindness o ceguera de género (Hoff, 2012) ha dejado invisible a la mujer a la luz de los análisis económicos del desarrollo, imprimiendo con este la preexistencia 
de relaciones desiguales entre los géneros, exponiéndolas a que habitualmente reciban impactos dañinos desde las políticas implementadas.

De esta forma se entiende que los fenómenos económicos ocurridos desde los inicios de la década de los noventa en Colombia han producido cambios, en algunos casos radicales, sobre los modos de producción y la evolución del empleo, sobre las relaciones entre el Estado y las estructuras sociales, así como sobre los vínculos entre el país y la comunidad internacional. Pero con el gender blindness el análisis económico y el proceso de desarrollo han terminado de agravar la calidad de vida y el progreso de la mujer colombiana, característicamente aquella que habita en las zonas rurales del país. Así entonces, los análisis del derecho económico inspirados en el género, en términos económicos, maximizarían la llamada "relación costo-beneficio", ensanchando la función de utilidad de cada agente económico que se mueve en el mercado (la mujer en este caso), con miras a obtener la mejor opción posible partiendo de los escasos recursos que se tienen en Colombia, de manera que se opte por la alternativa más "eficiente", incluyente y distributiva.

En pasados apartes se dejó claro que el derecho económico tiene un primordial protagonismo como gestor de los procesos de desarroIlo del país. Se dijo que el derecho económico debe comprometerse con crear escenarios de desarrollo que evidencien una justa y eficiente distribución de la riqueza nacional y permitan a la población acceder a los servicios básicos, estableciendo que es potencialmente ineludible desde este formular la igualdad o la reducción de las asimetrías como elemento sine qua non del desarrollo, transformando la estructura económica de producción y distribución para que se produzca un crecimiento equitativo, y exigiendo también programas de desarrollo e inversiones que no dependan únicamente de los mecanismos de mercado.

Desde esta representación, ¿cómo lograría esto el derecho económico en Colombia? y ¿cómo contribuiría a la supresión del gender blindness que ha agravado la calidad de vida y el proceso de desarrollo de la mujer colombiana?

Presumo que sería posible conteniendo en los análisis del derecho económico la perspectiva de género de la que tanto énfasis hemos hecho en este documento, y solo por medio de la aplicación del enfoque del gender mainstreaming a los procesos de análisis y formulación de las políticas de desarrollo en Colombia se contribuiría a la erradicación del gender blindness para mitigar los impactos negativos del desarrollo en la mujer colombiana.

\section{B. El gender mainstreaming}

Para comenzar hay que señalar que el gender mainstreaming no representa, hasta el momento, una propuesta acabada, y que incluso la denominación suele ser objeto de discusión y planteamiento de nombres alternativos, tales como: mainstreaming de género, transversalización de género, transversalización del enfoque de género, enfoque integrado de género o adopción de criterios de género, e incluso hay quienes plantean enfoque de género y empoderamiento, todas expresiones vinculadas a los procesos de 
políticas públicas. Finalmente, algunas personas hemos concebido la denominación institucionalización del enfoque de género en políticas públicas del desarrollo" (García, 2008).

El gender mainstreaming, que fue la expresión originalmente empleada en el seno de las $\mathrm{Na}$ ciones Unidas donde se planteó por primera vez, no encierra un producto sobre el cual se haya colocado el punto final. En realidad se ha venido enriqueciendo y planteándose a sí mismo nuevos desafíos conceptuales, metodológicos y técnicos, a medida que ha ido creciendo el aporte de las y los investigadores y teóricos sobre los problemas de la igualdad, la discriminación, las implicaciones de las diferencias y desigualdades de género, los nuevos paradigmas de la justicia y el desarrollo o la democracia y su inserción en las políticas públicas (García, 1988).

El gender mainstreaming nació a partir del enfoque denominado gender and development (GAD), en español género en el desarrollo, que se fundamenta en el Marco Analítico de la Universidad de Harvard, uno de los primeros modelos creados de análisis en función de género (Overholt, Anderson, Cloud y Austin, 1985).

En sus inicios el enfoque GAD apuntó a sacar a las mujeres de sus lugares de aislamiento y a dar visibilidad a las estructuras que hacen posible la inequidad de género. Sus herramientas fundamentales fueron, en primer lugar, los entrenamientos en género (gender training) con el doble objetivo de sensibilizar, por una parte, y capacitar, por otra. Algo completamente fundamental para lo que hoy denominamos los análisis de género. La incorporación del concepto de género desde el GAD constituyó, sin mencionarlo explícitamente, un primer intento de incorporar la perspectiva de género al mainstream de las políticas y las instituciones, lo que luego evolucionaría hacía del gender mainstreaming en la década de 1980 (Mooser, 1988).

Más tarde, al comenzar a evaluarse el impacto producido por la globalización y los modelos neoliberales sobre las mujeres de los países en desarrollo, que resultaron especialmente afectadas por la desregulación y el achicamiento o la destrucción de la infraestructura social, se hizo indudable que ni los procesos económicos ni los conceptos científicos que los explicaban eran neutrales en términos de género. Las mujeres habían sufrido más que los hombres las consecuencias negativas de los procesos de desarrollo. En este marco, el gender mainstreaming apareció como el instrumento más adecuado para analizar el impacto diferencial sobre mujeres y varones de los procesos macroeconómicos y políticos (onu, 1992).

Fue así como, adoptado primero por las instituciones que promovían políticas para el desarroIlo, el gender mainstreaming comenzó a proyectarse en la arena macropolítica a partir de la IV Conferencia Mundial de la Mujer, de Beijing. La Plataforma de Acción de Beijing puso en claro la existencia de sistemas de género en las distintas sociedades, el funcionamiento desigual de estos y las diferentes dimensiones de los problemas y desigualdades de género que son resultado de este carácter sistémico: simbólica, normativa, subjetiva y relacional. Se reconoce que ningún campo es neutral al género y que es necesario profundizar el análisis multicausal 
y la integralidad de la acción, y que el Estado es el responsable de hacerlo. En este contexto, se rejerarquiza el rol de las oficinas de la mujer, que se conciben como instancias de coordinación de políticas, responsables de liderar el proceso de gender mainstreaming e influir ya no solo en las políticas específicamente orientadas a la mujer, sino en el conjunto de las políticas públicas (PNUD, 2000).

Producto entonces de su proceso de construcción, tres de las definiciones clásicas que aparecieron posteriormente y que son casi referencia obligada en casi todas las reflexiones sobre el tema, son:

\section{Gender Mainstreaming}

\begin{tabular}{|c|c|}
\hline $\begin{array}{l}\text { Definición del Consejo Económico y } \\
\text { Social de Naciones Unidas (1997) }\end{array}$ & Definición del PNUD (2000) \\
\hline $\begin{array}{l}\text { "Mainstreaming a gender perspec- } \\
\text { tive is the process of assessing the } \\
\text { implications for women and men of } \\
\text { any planned action, including legis- } \\
\text { lation, policies or programmes, in all } \\
\text { areas and at all levels. It is a strategy } \\
\text { for making women's as well as men's } \\
\text { concerns and experiences an integral } \\
\text { dimension of the design, implemen- } \\
\text { tation, monitoring and evaluation of } \\
\text { policies and programmes in all politi- } \\
\text { cal, economic and societal spheres so } \\
\text { that women and men benefi t equa- } \\
\text { Ily and inequality is not perpetuated. } \\
\text { The ultimate goal is to achieve gen- } \\
\text { der equality." }\end{array}$ & $\begin{array}{l}\text { El género en el mainstreaming } \\
\text { tiene como propósito integrar } \\
\text { el interés en la igualdad de gé- } \\
\text { neros en todas las políticas, pro- } \\
\text { gramas, procedimientos admi- } \\
\text { nistrativos y financieros y en el } \\
\text { marco cultural de la institución } \\
\text { u organización. Más específica- } \\
\text { mente es una estrategia para } \\
\text { asegurar que: 1) la igualdad de } \\
\text { hombres y mujeres esté inclui- } \\
\text { da en todas las fases menores o } \\
\text { mayores del proceso de toma de } \\
\text { decisiones de una organización, } \\
\text { 2) y que el producto o resultado } \\
\text { de las decisiones que se hayan } \\
\text { tomado sea sistemáticamente } \\
\text { monitoreado en lo que se refie- } \\
\text { re a su impacto en la igualdad de } \\
\text { géneros. (... ) Una iniciativa efec- } \\
\text { tiva de género en el mainstream } \\
\text { requiere la interacción comple- } \\
\text { ja de numerosas habilidades y } \\
\text { competencias usualmente coor- } \\
\text { dinadas en un equipo de trabajo } \\
\text { integrado para tal fin. }\end{array}$ \\
\hline
\end{tabular}

Definición del Consejo de Europa (1998)

Gender mainstreaming implica la reorganización, fortalecimiento, desarrollo y evaluación del proceso de las políticas públicas, a fin de que la perspectiva de la igualdad de género sea incorporada en todas las políticas, a todos los niveles y en todas sus fases, por los actores normalmente involucrados en su elaboración.

Fuentes: Reporte del Consejo Económico y Social 1997. A/52/3, 18 de septiembre 1997. Chapter IV: Mainstreaming the gender perspective into all policies and programs in the United Nations System. Documento en línea de la División para el Adelanto de la Mujer. ONU. Traducción libre de Evangelina García Prince. 43 UNDP: Gender and Development Program. Learning and Information Pack. NY. 2000. Documento en línea del programa. Versión libre de Evangelina García Prince.

**Sistematización y elaboración de la autora Evangelina García Prince para el Proyecto Regional de PNUD "América Latina Genera: Gestión del Conocimiento para la Equidad de Género en Latinoamérica y El Caribe", a partir de la obra The United Nations and the advancement of Woman. 1945 - 1995. United Nations. New York. 1995. 
En estas definiciones quedan claramente establecidos los siguientes supuestos, que hoy por hoy son ampliamente compartidos (Navarro, 2007):

a. El gender mainstreaming es un proceso estratégico. Es una estrategia, no es un fin en sí mismo, el fin es la igualdad; con lo cual podemos entender que de cierta manera representa una opción, un instrumento estratégico para alcanzar la igualdad. De esta primera aproximación podemos deducir, elementalmente, que el empleo del gender mainstreaming exige el empleo de herramientas estratégicas. Esto, que puede parecer una simpleza, no lo es de cara a algunas experiencias concretas observables en esfuerzos nacionales o locales de algunos países que se proponen, por ejemplo, planes de igualdad bajo la denominación de mainstreaming de género y para su diseño solo emplean herramientas normativas, donde no existen los diagnósticos estratégicos que habría que desarrollar para varias tareas y donde el plan mismo carece de esta condición.

b. El gender mainstreaming tiene como propósito el logro de la igualdad de mujeres y hombres, con lo cual hay un tácito reconocimiento de que la desigualdad es un problema público. Supone considerar la eliminación de las desigualdades de género y el establecimiento de la igualdad, como dimensión o referencia indispensable en todas las fases del proceso de políticas públicas (y aun en el caso de las políticas de las organizaciones privadas que promueven políticas de igualdad), así como en el orden institucional y organizacional que les da soporte, en su ejecución y evaluación. Este es el sentido del término inglés mainstreaming, que aproximadamente significa en español "la corriente principal" y cuyo sentido, en este caso, creemos que se aproxima a la idea de que el principio de igualdad impregne como referencia sustantiva las decisiones de política y su implementación y evaluación. Este último aspecto se torna vital dado el hecho de que, como ambas definiciones expresan, es de la mayor importancia monitorear los impactos diferenciales que las decisiones tienen en mujeres y hombres.

c. Su aplicación abarca todos los órdenes y niveles de la gestión institucional u organizacional: leyes y todo otro mandato de políticas, programas y proyectos en todas las áreas y niveles sociales, políticos, culturales y económicos.

d Debe ser asumido en todos los aspectos o fases operativas de la gestión o proceso de las políticas: diseño, implementación, monitoreo y evaluación.

e. Sus criterios metodológicos fundamentales son:

1. integrar globalmente las experiencias, los intereses y las necesidades de las mujeres y de los hombres en todas las iniciativas de cualquier tipo y alcance;

2. evaluar las implicaciones que tenga cualquier acción realizada en mujeres y hombres;

3. garantizar beneficio igual para hombres y mujeres. 
f. Supone contar con el apoyo de un equipo calificado a cargo de la dirección, coordinación y apoyo a la ejecución de las tareas correspondientes.

Estos supuestos esenciales constituyen el corazón mismo del gender mainstreaming y alrededor de ellos se ha venido construyendo el conjunto de requerimientos y operaciones que exige su real cumplimiento. No se trata entonces de una acción, programa o estrategia singular, sino, como su nombre indica, una presencia integrada e integral en todas las decisiones y acciones de las organizaciones inmersas en el desarrollo.

\section{El gender mainstreaming en los aná- lisis del derecho económico colombiano de cara a los procesos de desarrollo}

\section{Los inicios}

En Colombia, la oficina del PNUD logró situar la llamada Estrategia de género 2007-2008, con el objetivo de institucionalizar e integrar el género en todos sus ámbitos de trabajo (PNUd Colombia, 2008).

La estrategia incorporó los principales mandatos y acuerdos internacionales en materia de desarrollo y género, y los mandatos del Consejo Económico y Social relativos a la inclusión del enfoque de género en todas las políticas y programas del sistema de Naciones Unidas. En un primer intento la oficina en Colombia adaptó el concepto de Transversalidad de género (TG) del denominado Guidance Note on Gender Mainstreaming (onu, 2002).
Así, aprobado por la Junta Directiva del PNUd Colombia en 1997, se asume la transversalización de género como una transformación profunda de la organización en todos los niveles. Sin embargo, dada la actual situación de redefinición de la estructura interna de la oficina de Colombia, se consideró viable comenzar el proceso de tg focalizando los esfuerzos en el área de programas. Por ello, la estrategia en Colombia solo se centró fundamentalmente en el fortalecimiento de las capacidades técnicas para la TG del personal del área de programas y en la identificación y priorización de acciones positivas y de género al interior de los programas ya en marcha o en proceso de definición.

Es significativo señalar que tal propuesta no fue concebida como una política nacional que aprobara incorporar acciones tendientes a promover un cambio económico y político a favor de relaciones de género más equitativas en los procesos de desarrollo nacional desde los análisis económicos del desarrollo formulado y plasmado en políticas, sino que fue implementada como un programa piloto de sensibilización a funcionarios y programas internos que sobre la equidad de género, tuvieran un tipo de impacto sectorial. Por lo que en Colombia, si bien es clara la existencia de un primitivo avance para la aplicación del gender mainstreaming, es importante fijar que no hay certeza política y científica sobre su empleo en los análisis del derecho y la economía en lo que concierne a los procesos de desarrollo. 


\section{La propuesta propiamente dicha}

El gender mainstreaming se propone en los análisis del derecho económico como un proceso de cambio que demanda una perspectiva estratégica capaz de replantear las dimensiones sociales que podrían (o convendrían) caer bajo su influencia. Pero idénticamente, las dimensiones institucionales de las políticas y los procesos de desarrollo que lo ponen en marcha, las implicaciones que en otros órdenes sociales como los de raza, edad, etnia, clase y otros deberían ser razonadas colectivamente, así como los patrones identitarios dominantes que aparecen dentro del sistema colombiano de las relaciones de poder entre los géneros. Análisis que efectivamente no existe en Colombia. Esto significa que para un cambio como el que se propone desde el derecho económico, la estrategia exigiría liquidar las desigualdades de género, una perspectiva progresiva de mediano o largo plazo donde se asuman las necesarias factibilidades políticas del desarrollo, que no dependen solo de la preexistencia de voluntad política sino de los procesos de legitimación de las iniciativas, para evitar que la propuesta se convierta en un anuncio de "guerra entre los sexos" como a menudo enuncian quienes se resisten desde sus actitudes a la equidad de género en el desarrollo.

Se propone, igualmente, que desde los análisis del derecho económico aplicados al desarrollo, se haga un trabajo estratégico con las condiciones del contexto social donde puedan aparecer las reales y efectivas oportunidades, lo que le exigirá al derecho económico trabajar claramente con propuestas y previsiones de empodera- miento y sensibilización fuera del marco de los actuales análisis de la pura teoría económica, cumpliendo de forma indefectible con los postulados de distribución, asignación y equidad que establece la norma constitucional en el artículo 334 para los procesos de desarrollo en nuestro país.

El gender mainstreaming suprimiría la invisibilidad de la mujer en los análisis del derecho económico en Colombia, porque instalaría una visión de desarrollo complementado con las acciones de integración de la mujer a estos. Igualmente, generaría la integración de la mujer a la producción, en condiciones de igualdad en cuanto a oportunidades y estímulos, pues ella sería un referente obligatorio de análisis económico de la sociedad colombiana. Lo que reforzaría todas aquellas instancias organizativas de mujeres que les permitan tomar conciencia de su subordinación de género, clase, etnia, etcétera y asumirse como fuerza política desde la economía y el desarrollo.

Por tanto, un requisito indispensable del gender mainstreaming desde el derecho económico en Colombia, para la erradicación de la invisibilidad de la mujer, sería la capacidad de negociación e interlocución directa con otras organizaciones económicas y con el Estado, para que con la demostración de análisis eficientes desarrollen espacios e instancias que les permitan crecer como personas a su propio ritmo. 


\section{Componentes básicos del gender mainstreaming en los análisis del dere- cho económico en Colombia}

La aplicación del gender mainstreaming como enfoque propuesto a los análisis del derecho económico en Colombia deberá considerar los tres componentes fundamentales que implica instalarlo en el análisis de los procesos de desarrollo de un país: el contexto, la aplicación del proceso de análisis de la asimetría de género en el desarrollo, las estructuras y mecanismos (PNUD, 1997).

\section{El contexto de inequidad}

Hace referencia al análisis incluyente que refleja la situación socioeconómica del país, dimensionando los datos desagregados por sexos en la participación laboral, el desempleo, la participación social y política, educación, salud, violencia de género, emigración e índice de desarrollo humano.

Desde el derecho económico en Colombia, se efectuaría bajo un análisis que demuestre una real prosperidad o un real fracaso, no solo en términos de la factibilidad política del desarroIlo, sino en términos de las bases jurídicas o normativas adecuadas que acuerdan el bienestar fáctico de la mujer. Es decir, que el derecho económico en esta faceta deberá analizar si en Colombia hay mujeres incluidas en la toma de decisiones y con un soporte financiero digno, considerando la incidencia de las desigualdades de género en la situación general de la sociedad, que a ellas las afecta en todos los grados.

\section{La aplicación del proceso de análisis de las asimetrías de género en el desarrollo}

Hace referencia al análisis que permite conocer los complejos procesos para explicar cómo se están estructurando y expresado los ámbitos de lo femenino y lo masculino y cuáles son los símbolos y características que los definen y representan como construcciones culturales opuestas y simétricas en el proceso de desarrollo. Esta fase del gender mainstreaming coloca en evidencia las relaciones simétricas o asimétricas entre hombres y mujeres en el desarrollo, el rol social asignado a cada sexo y la adquisición e identidad genérica que mejora o empeora la realización de los sexos en los procesos de desarrollo social y económico.

La aplicación del proceso en Colombia no liará el acogimiento de los criterios de igualdad de género en los procesos de planificación para el desarrollo, sino que el análisis desde el derecho económico involucrará el diseño de un plan nacional de igualdad de género acorde con las necesidades reales de la mujer desde los sectores identificados, todo ello soportado por la creación de las estructuras y mecanismos necesarios revelados por el contexto, que concierten las necesidades reales de la mujer en el desarrollo del país.

\section{Las estructuras y los mecanismos}

Hacen referencia a la existencia institucional de entidades encargadas de la aplicación de programas de reconstrucción para la equidad en el desarrollo, desde una perspectiva de género, 
que permite reconocer no solo las necesidades de las personas sino también sus estrategias y sus acciones para ayudarse a sí mismas, contribuyendo a reconocer la existencia de relaciones desiguales entre hombres y mujeres, lo que constituye la base para conocer las diferentes necesidades y capacidades de ambos, especialmente de la mujer.

En Colombia, las estructuras harán referencia a las instituciones responsables de la estrategia, que deben tener las condiciones básicas para ser desconcentradas en puntos focales, articuladas al organismo que liderará el proceso, el cual deberá contar a su vez con un equipo con capacidades para conducirlo y gerenciarlo, siguiendo todas el análisis revelado por el diseño del plan desde la aplicación del proceso de análisis de las asimetrías de género en el desarroIlo. Los mecanismos serán los instrumentos variados que utilizará en todo momento el derecho económico para generar el impacto de género sobre los procesos de desarrollo, los cuales serán en todo momento:

a. el constante análisis de género,

b. la producción y procesamiento de información,

c. la concientización y capacitación, y

d. el seguimiento y evaluación

A esto se le conocería como un verdadero "análisis del derecho económico con un enfoque basado en género", caracterizado principalmente por el estudio de las políticas y de las instituciones en el marco de un modelo de Estado constitucional, tanto desde la perspectiva positiva (de la explicación y predicción de relaciones de causa y efecto de lo existente) como desde la normativa (del deber ser, más allá de la explicación y la predicción, utilizando juicios de valor y distribución equitativa), que logre racionalizar la economía con el fin de conseguir el mejoramiento de la calidad de vida de todos y todas. Con esto se provocaría la participación femenina en el proceso de desarrollo del país y la economía, consiguiendo la mujer colombiana reivindicarse en posiciones directivas en las empresas y en el gobierno, lo que indudablemente, de forma natural, generaría un bienestar fructífero para ellas y para todos.

\section{CONCLUSIONES}

1. La Constitución de 1991 incorporó esquemas y normas fundamentales que posibilitan reconocer la valoración de las capacidades humanas en el régimen económico colombiano, generando un avance significativo en el proceso de humanización del desarrollo socioeconómico del país.

2. El derecho económico, coordinado con el desarrollo del país, debe responder a la exigencia de valorar las capacidades y competencias humanas que establece la Constitución Política, tomando como punto de partida el principio de participación equitativa que avala la realización social de los derechos constitucionales y económicos de todas y todos.

3. La valorización de las capacidades humanas en el contexto de prometer acceso a los menos favorecidos, como lo es el caso de la mujer co- 
lombiana, solo es posible mediante la alianza derecho económico y género. Lo que significaría la coexistencia pacífica entre los poderes concedidos por el sistema constitucional a la economía y las libertades públicas que el mismo sistema garantiza para la realización de los ciudadanos.

4. La perspectiva de género inmersa en las relaciones del derecho económico favorecería a la mujer, en razón a que la sociedad colombiana le sigue fallando particularmente en su realización socioeconómica y en momentos claves de su vida (adolescencia y vejez), pese a que se han realizado algunos progresos desde el derecho y la economía auspiciados por la Constitución Política.

5. La alianza entre derecho económico y género, con fundamento en la aplicación del gender mainstreaming como mecanismo para hacer realidad la erradicación de la invisibilidad de la mujer en los procesos de desarrollo en Colombia, denotaría principales cambios en las relaciones laborales y en las condiciones de trabajo, surgidos a raíz de los programas de ajuste estructural y de las transformaciones ocurridas como consecuencia de dicho enfoque en la economía del país. Además, reivindicaría la obligatoriedad de los conceptos de participación y distribución equitativa en los sectores activos de la economía, como muestra eficaz de acciones reales que fijen la aparición de un enfoque en la asignación de roles sin discriminar competencias humanas.

6. El objetivo de la alianza derecho económico y género ampliaría y fortalecería la respuesta del sector económico, reuniendo pruebas, aplicando criterios de orden constitucional para incorporar la igualdad entre hombres y mujeres en las políticas y los programas que la Constitución fijó desde su expedición, y subsanaría las anomias jurídico-económicas de prestaciones productivas de la mujer en los entornos sociales, obteniendo la supresión de los efectos adversos comunes y diferenciados de la economía sobre el ejercicio de los derechos económicos de las mujeres como amenaza para su autonomía.

7. La propuesta de los análisis del derecho económico a los procesos de desarrollo social y económico del país con un enfoque basado en género, caracterizaría principalmente un cambio en el estudio de las políticas públicas y de las instituciones, en el marco del actual Estado constitucional modificando la perspectiva, tanto positiva de la explicación y predicción de relaciones causa-efecto de lo existente respecto al empoderamiento de la mujer como la normativa del deber ser, más allá de la explicación y la predicción, utilizando juicios de valor y distribución equitativa que logren racionalizar la economía con el fin de conseguir el mejoramiento de la calidad de vida de la mujer colombiana.

8. Finalmente, los análisis del derecho económi$\mathrm{co}$, de cara a los procesos de desarrollo social y económico del país con un enfoque basado en género en la aplicación del gender mainstreaming, permitiría establecer los fundamentos de un modelo económico y social de desarrollo y equidad, con énfasis en la brecha entre los aportes que las mujeres realizan a las economías del país y los beneficios que reciben. 
Bibliografía

Ackerman, B. y Golove, D. (1995). "Is NAFTA Constitutional". Cambridge: Harvard University Press.

Alviar García, H. (8 de diciembre del 2001). Leon Duguit and the 1936 Colombian Constitutional Reform. Trabajo presentado en Harvard Law School.

AmARTYA, S. (1998). "Concepto de desarrollo humano". Programa de los Informes Nacionales de Desarrollo Humano y Objetivos del Desarrollo del Milenio. Guatemala.

Arango, L. E., Flórez, L. A. y Arosemena, A. M. (2004). "El tramo corto de la estructura a plazo como predictor de expectativas de actividad económica en Colombia". Borradores de Economía, $\mathrm{n}^{\circ}$. 279. Banco de la República, Colombia.

ARIÑo, G. (2012). La regulación económica. Aranzadi.

Arndt, H. W. (1987). Economic Development: The History of an Idea. Chicago: University of Chicago Press.

Barenboim, P. (2001). "Constitutional Economics and the Bank of Russia". In: Fordham Journal of Corporate and Financial Law.

BeneríA, L. (2001). “The Enduring Debate over Unpaid Labour". In: Loutfi, Martha Fetherolf. Women, Gender and Work: What is Equality and how do we get there? Geneva: ILo.
Bravo, D., Contreras, D. (Abril de 2004). La distribución del ingreso en Chile 1990-1996: análisis del impacto del mercado de trabajo y las políticas sociales. En Reformas y equidad social en América Latina y el Caribe. Memorias de la primera fase del foro de equidad social. Capítulo 6, (99-128). Banco Interamericano de Desarrollo.

Calderón, V. (2011). La constitucionalización del derecho privado. La verdadera historia del impacto constitucional en Colombia. Bogotá: Temis.

Carrasquilla, A. (2001). "Economía y Constitución: hacia un enfoque estratégico". En: Revista de Derecho Público, $\mathrm{n}^{\circ} .12$.

Castillo, F. (1992). "Aspectos doctrinales". En: Elementos económicos en la Constitución Política, San José, Costa Rica: Ed. Juritexto.

CeA, J. L. (1979). Tratado de la Constitución de 1980. Santiago: Universidad de Chile.

Contreras, D. (2003). "Poverty and inequality in a rapid growth economy". In: Journal of Development Studies.

Daeren, L. (2001). “Enfoque de género en la política económica-laboral. El estado del arte en América Latina y el Caribe". Serie Mujer y Desarrollo, n. 29. Santiago: CEPAL.

Dane. (2010). Estadística sobre la diferencia de género en el entorno laboral en Colombia en las principales ciudades. Bogotá: DanE. 
DANE. Género en Colombia 2011-2012. Recuperado desde: http://www.dane.gov.co/files/ investigaciones/boletines/especiales/genero/bol_genero_2011.pdf

De Melo, J. (1991). Fiscal Issues in Adjustment: an Introduction. California: California University Press and World Bank.

Del Vecchio, G. (1967). La teoría económica del crédito. Centenario della Nascita. Milán: F. Angeli.

Diez, M. (1996). “Deporte y construcción de las relaciones de género". En: Gazeta de Antropología 12: 93-100.

Domínguez, E. (2005). Equidad de género en la educación ¿que hemos logrado las mujeres colombianas? Bogotá: Centro de Estudios Sociales, Facultad de Ciencias Humanas, Universidad Nacional de Colombia.

Gálvez, T. (2001). Aspectos económicos de la equidad de género. Serie Mujer y Desarrollo $n^{\circ}$. 35. Santiago: Cepal.

García, A. I. (1988). Conquista, compromiso y cambios de políticas públicas para la equidad de género en la era post Beijing. Documento de Trabajo. San José de Costa Rica: Fundación GESO.

García, E. (1988). Género, políticas locales e intervención social: un análisis de los servicios de bienestar social municipal para la población femenina en España. Madrid: Instituto de Investigaciones Feministas.
García, E. (2008). Proyecto regional de pNUd América Latina Genera: Gestión del Conocimiento para la Equidad de Género en Latinoamérica y el Caribe. San Salvador: PNUD.

Giddens, A. (1974). Positivism and sociology. Londres: London School of Economics and Political Science.

Green, F. (1979). "The Consumption Function: A Study of a Failure in Positive Economics". In: Francis Green y Petter Nore (Eds.). Issues in political economy: A critical approach. London: Macmillan.

HaRVEY, C. R. (1997). "The relation between the term structure of interest rates and Canadian economy growth". Canadian Journal of Economics.

Hoff, B. H. (2012). “The National Intimate Partner and Sexual Violence Survey and the perils of advocacy Research". Men Web Online Journal, vol. 2, Issue 3. Recuperado desde: http:// batteredmen.com/NISVS-PerilsAdvocacyResearch.pdf

Holesovsky, V. (1977). Economic Systems: Analysis and Comparison. McGraw-Hill.

Hoyos Rojas, L. M. (2012). “El método neoconstitucional de la dignidad en el derecho privado: una aproximación a la igualdad de género en el ámbito de las relaciones familiares homoparentales". En: Revista de Derecho Privado, $n^{\circ} .47$. 
Kalmanovitz, S. (2001). Las instituciones y el desarrollo económico en Colombia. California: California University Press. Adaptado en Colombia por el Grupo Editorial Norma.

Kumar, S. y López, G. (2001). "La perspectiva de género en las políticas y prácticas comerciales entre la Unión Europea y América Latina". En: Cuadernos Feministas.

Kwan, M. (2008). “Feminist Perspectives on Geographic Information Systems: Implications for Geographic Research". In: L. Schlesinger (ed.). Gendered Innovations in Science and Engineering. Stanford: Stanford University Press.

Layne \& Shawrs. (1993). "American Hegemony Without an Enemy". In: Foreign Policy, n. 92, United States.

LIGHT, A. \& LuCkIN, R. (2008). Designing for Social Justice: People, technology, learning. London: Futurelab, Innovations in Eudcation.

López Hurtado, C. (1994). "Política económica y política social: una sola estrategia para la modernidad". En: Examen, n. 62.

Messep, Misión. (2002). Informe de género de la misión de empalme de las series de empleo, pobreza y desigualdad. Bogotá, Colombia.

Millán de Benavides, A., Estrada, A. M. (2004). El concepto de 'género' y sus avatares: interrogantes en torno a algunas viejas controversias. En Pensar (en) Género. Teoría y práctica para nuevas cartografías del cuerpo. Bogotá: Editorial Pontificia Universidad Javeriana.
Moser, C. (1988) "Gender Planning in the Third World: Meeting Practical and Strategic Gender Needs". World Development.

Navarro, N. (2007). Desigualdades de género en las organizaciones: proceso de cambio organizacional pro equidad. Recuperado desde: http://www.americalatinagenera.org/biblioteca/detalle. php?IDPublicacion $=477$

OEA. Plan estratégico de cooperación solidaria para el desarrollo integral 2006-2009. Recuperado desde: http://www.oas.org/es/becas/ programaregular/docs/plan_estrategico.pdf

Oıт. (2012). Género y Desarrollo. Recuperado desde: http://www.ilo.org/global/topics/ economic-and-social-development/genderand-development/lang--es/index.htm

Oıт. La igualdad de género. Recuperado desde: http://www.ilo.org/public/spanish/gender. htm

Onu. Gender Mainstreaming an Overview. (2002). Recuperado desde: http://www. un.org/womenwatch/osagi/pdf/e65237.pdf

Onu. (1992). Consejo Económico y Social. Comisión de la Condición Jurídica y Social de la Mujer: temas prioritarios. "Igualdad: eliminación de la discriminación de jure y de facto contra la mujer". Informe del Secretario General. Documento: E/CN.6//7.

Overholt, C., Anderson, M. B., Cloud, K., and AusTIN, J. (1985). "Gender Roles in Development Projects: Cases for Planners West Hartford". Cambridge: Harvard University Press. 
Pnud. (2010): “Gender and Development Program. Learning and Information Pack. N. Y. Documento en línea del programa. Versión libre de Evangelina García Prince.

PNud. (2006): “Gender and Development Program. Learning and Information Pack. N. Y. Documento en línea del programa. Versión libre de Evangelina García Prince.

PNud. (2006): “Gender and Development Strategy Colombia". N. Y. Documento en línea del programa. Versión libre de Evangelina García Prince.

PNud. (2005): “Gender and Development Program. Learning and Information Pack. N. Y. Documento en línea del programa. Versión libre de Evangelina García Prince.

PNud. (2000). "Gender and Development Program. Learning and Information Pack". N. Y. Documento en línea del programa. Versión libre de Evangelina García Prince.

PNud. (1997). Guidance Note on Gender Mainstreaming aprobada por la Junta Directiva del PNUD en 1997. Recuperado desde: http://www.pnud.org.co/img_upload/ 196a010e5069f0db02ea92181c5b8aec/ Estrategia\%20de\%20genero\%20PNUD\%20 Colombia.pdf

Sanchís, N. y Baracat, V. (2004), “Introducción a la perspectiva de género". Material elaborado para el Seminario Virtual sobre Género y Comercio, Red Internacional de Género y Comercio. Recuperado desde: www.generoycomercio.org
Stern, S. J. (1999). La historia secreta del género. Mujeres, hombres y poder en México en las postrimerías del período colonial. México: FCE.

Stiglitz, J. (2002). "Peasants Versus City-DweIlers: Taxation and the Burden of Economic Development". Oxford: Oxford University Press.

Strassman, D. (1999). "Feminist Economics". In: Peterson, Janice y Margaret Lewis (eds.) The Elgar Companion to Feminist Economics. Cheltenham, U. K.: Edward Elgar.

TruBEK, D. y DeZalay, Y. (1997). “La internacionalización de los campos jurídicos y la creación de espacios transnacionales". En: Pensamiento Jurídico, Bogotá: Universidad Nacional.

\section{NORMAS Y JURISPRUDENCIA}

CONSTITUCIÓN POLÍTICA. (1991). Diario Oficial de la República de Colombia.

\section{CORTE CONSTITUCIONAL}

Sentencia C-136 (1999).

Sentencia C-150. (2003).

Sentencia C-233. (1997).

Sentencia C-776 (2003). 